\section{É POSSIVEL EXISTIR DIÁLAGO ENTRE O SABER DO CAMPO E O SABER ESCOLAR, POR MEIO DO CURRÍCULO?}

\author{
DIÁLAGO THERE IS POSSIBLE \\ BETWEEN KNOWLEDGE AND KNOW \\ THE FIELD SCHOOL THROUGH THE \\ CURRICULUM?
}

\author{
Natalia Ossoski Milani ${ }^{19}$ \\ Rosangela Valachinski Gandin ${ }^{20}$
}

Resumo: O objetivo do trabalho consiste em buscar conhecimentos metodológicos para compreender como se constrói, executa e vivencia um Currículo Escolar que visa atender educandos oriundos do campo e da cidade, matriculados numa Instituição de Ensino Nucleada. A metodologia foi organizada em três etapas. A primeira correspondeu a avaliação diagnóstica, a segunda corresponde, respectivamente, a 22 horas aulas, organizadas em 08 encontros de atividades sobre o conteúdo "medidas agrárias", e a terceira etapa, diz respeito a avaliação somativa. Trinta estudantes da $3^{\text {a }}$ série do ensino médio participaram das atividades, que reúne 28 horas de trabalho. Como resultado foi obtido que a metodologia desenvolvida contribuiu com a aprendizagem e a formação dos estudantes, por isso, o conteúdo "medidas agrárias" passou a fazer parte do Plano de Trabalho Docente - PTD e se incorporou ao currículo da escola do campo nucleada, de forma a criar permanente diálogo entre o saber popular e o saber escolar.

\footnotetext{
19 Professora e Pedagoga da Rede Estadual de Ensino do Estado do Paraná. Especialista em Educação do Campo. e-mail: natalimilani@yahoo.com.br.

${ }^{20}$ Pedagoga e Mestre em Educação. Pedagoga da Universidade Federal do Paraná - Setor Litoral. Coordenadora do Programa de Extensão O mundo mágico da leitura. E-mail: gandin_valachinski@yahoo.com.br.
}

Palavras-chave: Currículo Escolar. Educação no Campo. Metodologia de Ensino.

Abstract: The objective is to seek methodological knowledge to understand how to build, run and experiences a school curriculum that aims to meet students from the countryside and the city, enrolled in an educational institution seeded. The methodology was organized in three stages. The first corresponded to diagnostic evaluation, the second corresponds, respectively, to 22 hours classes, organized activities in 08 meetings over the content " agrarian measures ", and the third stage concerns the summative evaluation. Thirty students from the 3rd grade of high school participated in the activities, which includes 28 hours of work. The result was that this methodology contributed to the learning and teaching of students, so content " agrarian measures " became part of the Plan of Teaching Work - PTD and was incorporated into the school curriculum of the seeded field, so to establish permanent dialogue between popular knowledge and school knowledge .

Keywords: School curriculum. Education in Countryside. Teaching Methodology.

\section{Introdução}

O trabalho teve como meta principal buscar conhecimentos metodológicos para compreender como se constrói, executa e vivencia um Currículo Escolar que visa atender educandos oriundos do campo e da cidade, matriculados numa Instituição de Ensino Nucleada, isto porque o currículo é norteador do trabalho do professor, sendo que a elaboração e a execução precisam atender as necessidades e interesses dos 
estudantes, tendo em vista que cada escola é o resultado de um processo de desenvolvimento atrelado as suas contradições, portanto não existem escolas iguais e dessa forma o Currículo de cada Instituição é único, pois deve ser construído a partir de suas necessidades, buscando a direção necessária para atender a todos seus educandos em suas especificidades.

Por isso, buscaram-se por meio de estudos de teorias específicas, os conhecimentos que deem subsídios para a construção de um Currículo diversificado de forma a atender não somente a legislação, mas as especificidades dos estudantes e da escola, uma vez que o não reconhecimento dos adolescentes e jovens no/do campo é resultado de um processo histórico de não reconhecimento destes povos como sujeitos de direitos. Neste sentido, o deslocamento no sentido campocidade pela nucleação de escolas que apresenta como um de seus princípios a igualdade de oportunidades nega a estes jovens do campo conforme aponta Fernandes (2006) o direito de pensar o mundo a partir de onde vive e de sua realidade.

$\mathrm{Na}$ escola nucleada tempos diferenciados se encontram ou se desencontram; temporalidades com outros significados e valores que apesar de articulados e complementares, não elimina as especificidades e modos de vida próprios de cada um destes espaços, visto que possuem, "tempos diferenciados, movidos por lógicas distintas, mas não excludentes. [...]. Relações que se estabelecem sobre bases diferenciadas, determinando hábitos e sociabilidades distintas”. (BAGLI, 2006 p.82).

\section{Como se constitui o currículo escolar}

Tradicionalmente, as escolas têm a sua prática pedagógica determinada ou por orientações oriundas das secretarias de educação ou pelos próprios livros didáticos. Isso resulta, na maioria das vezes, em uma prática curricular muito pobre, que não leva em conta nem a experiência trazida pelo próprio professor, nem a trazida pelo educando, ou, mesmo às características da comunidade em que a escola está inserida. Por outro lado, isso restringe a autonomia intelectual do professor e o exercício da sua criatividade. E pior: não permite que a escola construa sua identidade. Para Sacristán:

\footnotetext{
$\mathrm{O}$ professor não decide sua ação no vazio, mas no contexto da realidade de um local de trabalho, numa instituição que tem suas normas de funcionamento marcadas às vezes pela administração, pela política curricular, pelos órgãos de governo ou pela simples tradição que se aceita sem discutir. (SACRISTAN, 2000 p.166).
}

Relacionada a isso, existe uma concepção restrita de currículo, próxima do conceito de programa, ou, pior ainda, de 


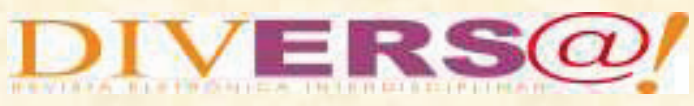

uma simples grade curricular, ou, de mera listagem dos conteúdos que devem ser tratados. Daí porque muitos professores se orientam apenas pelos sumários ou índices dos livros didáticos. $\mathrm{O}$ currículo, entretanto, abrange tudo o que ocorre na escola e fora dela.

\subsection{Possibilidades curriculares voltadas aos interesses dos alunos do campo}

O debate sobre a educação do campo vem crescendo de forma significativa nos últimos anos no Brasil, sendo impulsionado pelas lutas dos movimentos sociais do campo e a persistência de muitos educadores comprometidos com a transformação, tanto das políticas de educação desenvolvida no meio rural, quanto com as condições de exclusão social, negação de direitos e invisibilidade em que vive a população do campo.

As profundas transformações sociais, culturais, políticas, econômicas e ambientais ocorridas no campo e na cidade em decorrência dos avanços científicos e tecnológicos, provocaram grandes mudanças na área da produção.

Com os avanços da tecnologia e da informação ampliaram-se o acesso à internet, à televisão, aos outros meios de produção e difusão da informação e comunicação, resultando na mudança de comportamento, nos costumes e na forma de ser e pensar de muitos jovens do campo, pois observa-se que essas transformações ocorridas ainda causam inquietações e dúvidas em muitos educadores, tais como: que tipo de sociedade deve ser construída no meio rural? Qual o perfil do sujeito a ser formado para viver nesse campo em transformação? Quais os saberes, competências e habilidades os sujeitos devem possuir para pensar as políticas de desenvolvimento no campo, preservando os elementos históricos e culturais que alimentam a vida dos camponeses? Quais conteúdos devem ser priorizados no currículo das escolas como intuito de promover uma formação crítica dos jovens, comprometida com a construção de políticas de desenvolvimento que fomente a preservação do patrimônio ambiental e cultural das comunidades rurais e possibilite a melhoria da qualidade de vida?

São questionamentos que exigem dos educadores um esforço, tanto na elaboração das propostas curriculares, quanto na articulação e diálogo com as comunidades no sentido de pensar o currículo em sintonia com suas necessidades formativas, pois:

\footnotetext{
A construção de propostas curriculares distanciada da realidade sócio cultural dos camponeses contribui para que "muitas pessoas passem a negar sua própria condição campesina, influenciadas pela ideologia do campo como elemento de atraso sociocultural e econômico". (MACHADO, 2009, p. 194).
} 
Diante de tal contexto, as escolas devem repensar seus currículos, tornandoos mais democráticos e abertos ao diálogo com os diferentes saberes produzidos para além dos contextos escolares e acadêmicos, possibilitando o encontro de saberes e a ressignificação das práticas educativas e suas finalidades.

Nesse sentido torna-se necessário que os docentes desenvolvam uma visão crítica acerca dos aspectos políticos e ideológicos que estão envolvidos no processo de construção do currículo, desconstruindo a ideia de neutralidade científica, disseminada sobre a produção das políticas curriculares.

A Lei de Diretrizes e Bases da Educação Nacional - LDBEN, editada em 1996, representa um avanço nessa luta das populações rurais ao fazer constar em seu texto-base as peculiaridades do campo, garantindo o direito a uma educação diferenciada e abrindo possibilidades para a construção e consolidação de escolas organizadas com outra concepção tanto em sua estrutura de gestão escolar quanto epistemológica e didático-metodológica. $\mathrm{O}$ Artigo 28 da LDBEN trata do tema:

$\mathrm{Na}$ oferta de educação básica para a população rural, os sistemas de ensino promoverão as adaptações necessárias à sua adequação às peculiaridades da vida rural e de cada região, especialmente:

I - conteúdos curriculares e metodologias apropriadas às reais necessidades e interesses dos alunos da zona rural; (BRASIL, 1996).
Portanto o desafio de desenvolver um projeto que contemple uma estrutura e uma dinâmica curricular, adaptadas à realidade agrícola, conectada às especificidades da agricultura familiar, implica transformar ideias e princípios em práticas concretas, ações que ultrapassem os espaços formais de sala de aula, possibilitando a manutenção do vínculo familiar e a condição de protagonista do jovem rural.

O fortalecimento de um currículo adaptado à realidade do campo permite o resgate da autoestima dos filhos e filhas dos agricultores familiares, a busca incessante e permanente da democratização do saber e a possibilidade concreta de superar o temor da exclusão social que no entender de Dupas (1999) manifesta-se de duas formas: pela impossibilidade de garantir a sobrevivência física ou pelo sentimento subjetivo de ressentimento por não desfrutar de bens, capacidades ou oportunidades que outros indivíduos desfrutam.

\section{Metodologia}

O trabalho foi realizado por uma professora de matemática do Ensino Médio, contou com 30 educandos de $3^{\text {a }}$ série, oriundos em sua maioria do campo, 


\section{DIVERS@!}

de escola nucleada ${ }^{21}$. Ao todo foram 28 horas de trabalho, organizado em três etapas, sendo que a primeira corresponde a avaliação diagnóstica, a segunda diz respeito as atividades desenvolvidas pelos estudantes sobre o tema medidas agrárias, denominada de Compreendendo as Medidas Agrárias, que contou com 22 aulas organizadas em 8 encontros e a terceira etapa, corresponde a avaliação somativa. O trabalho foi concluído com apresentação da apropriação dos conhecimentos na feira Multicultural da escola.

$\mathrm{Na}$ primeira etapa, avaliação diagnóstica, com o objetivo de investigar se o estudo das medidas agrárias seria relevante; se os estudantes sabiam a respeito das medidas agrárias; se as utilizavam no campo no dia a dia; e se a aprendizagem do tema "mediadas agrárias" ocorreria de modo aplicado a prática e significativo para os educandos, foi aplicado um questionário.

O resultado desta avaliação diagnóstica foi de que aproximadamente $85 \%$ dos estudantes e seus familiares

21 Nucleação trata-se de um procedimento político-administrativo que consiste na reunião de várias escolas isoladas em uma só, desativando ou demolindo as demais. INEP-MEC (2006, P. 116).

http:/www.mst.org.br/hhttp://pt.wikipedia.org/wiki/Movi mento_dos_Trabalhadores_Rurais_Sem_Terra; e http://www.brasilescola.com/sociologia/mst.htm, conheciam, faziam uso, ou buscavam ajuda de alguém que soubesse realizar cálculos com as medidas agrárias.

$\mathrm{Na}$ segunda etapa, Compreendendo as Medidas Agrárias, utilizou-se de diferentes estratégias de ensino para promover a aprendizagem, conforme descrição a seguir.

Encontro 01 aconteceu em 04 aulas e tinha como objetivo problematizar a aprendizagem do conteúdo de medidas agrárias por meio de uma pesquisa bibliográfica sobre "MST e a cubação de terra", realizada pelos estudantes com auxílio e acompanhamento da professora. A pesquisa foi realizada no laboratório de informática da escola Os itens: o que é movimento sem terra, que pessoas fazem parte do mesmo, qual a ideologia, curiosidades, algumas imagens os links ${ }^{2}$ foram indicativos da atividade.

Após a pesquisa bibliográfica os estudantes socializaram, em roda de conversa, com os colegas o que foi relevante e o que aprenderam ao acessar os sites. Para finalizar a professora fez comentários e complementações.

Encontro 02, que utilizou 4 aulas, os educandos foram orientados a pesquisar textos que se referiam ao tema "medidas agrárias" e também a "história das medidas agrárias". Como recurso para pesquisa, foram disponibilizados todas as mídias (rede de internet, livros, jornais, revistas, etc.) presentes na escola. 


\section{DIVERS@!}

Na sequência, nas próximas 4 aulas os estudantes apresentaram, em roda de conversa sucintamente aos colegas o que foi relevante e o que aprenderam de novo e entregaram uma cópia da pesquisa para a professora. A professora avaliou as apresentações e fez complementações quando necessário.

Encontro 03, em outras 2 aulas, foi estudado/lido coletivamente, onde cada aluno lia um trecho de parte do capítulo I do livro Escola em Movimento. A Conquista dos Assentamentos de Ana Cristina Hammel, Nilton José Costa Silva e Ritamar Andreta, que trata das origens das propriedades das terras brasileiras, lutas e conquistas.

Após a leitura, na mesma data, foi realizada uma mesa redonda, mediada pela professora, com o objetivo de refletir e partilhar o assunto estudado. Os estudantes escreveram individualmente uma síntese das ideias relevantes, como avaliação formativa da atividade.

Encontro 04, com duração de 2 aulas, foi estudado a história de algumas medidas, tais como: a polegada, o palmo, o pé a jarda, a braça, o passo, o cúbito, bem como as medidas agrárias por meio de textos e exercícios, conforme anexo 02 .

Encontro 05, com duração de 3 aulas, houve uma palestra com Engenheiros Agrônomos que deram explicações sobre as medidas convencionais usadas atualmente por bancos e cooperativas, como, também, esclareceram o uso das medidas não convencionais e suas transformações ou equivalência. Explicaram sobre o uso e a medição de terrenos com GPS. Aplicou-se uma lista de exercícios sobre cálculos de área em alqueires hectares, braça, litro, para que os educandos aprendessem a diferença de como se faz esses cálculos (medidas convencionais e não convencionais), bem como resgatar conhecimentos, conforme anexo 3.

Encontro 6, em 4 aulas, foi realizada uma visita a uma propriedade rural, de uma família dos estudantes, acompanhada por dois agrônomos, de uma cooperativa local. Nesse encontro os educandos puderam acompanhar na prática visualizando e manuseando o aparelho GPS e a corda de medir para ter noção de como se realizam as medições com GPS e com corda, ou seja, convencional e não convencional, bem como realizar os devidos cálculos e transformações. Em outras palavras, os estudantes foram organizados em pequenos grupos e acompanhados por agrônomo, percorriam uma área medindo-a e posteriormente realizavam o cálculo da área medida com auxílio de calculadora. Calcularam as transformações em hectares, alqueire, etc. e refletiam sobre as conclusões, sendo essas, mediadas pela professora e pelo agrônomo, ainda na propriedade rural. Essa 


\section{DIVERS@!}

atividade contou com o transporte escolar da prefeitura municipal.

Encontro 7, em 3 aulas da semana posterior à visita, a professora e os estudantes realizaram um seminário para fechamento da avaliação dos trabalhos e organização dos resultados/conhecimentos adquiridos para ser apresentado na feira Cultural do Colégio.

Encontro 8, que aconteceu na Feira Cultural do Colégio, com a presença dos pais/responsáveis pelos estudantes matriculados na instituição, estudantes e comunidade em geral, os educandos apresentaram o que compreenderam do tema "medidas agrárias", utilizando-se de cartazes explicativos e quando necessário, comentavam o assunto dando explicações para os participantes da feira interessados no assunto. Essa atividade aconteceu em um domingo, num total de 04 horas.

$\mathrm{Na}$ terceira etapa, Avaliação Somativa, foi aplicado o questionário utilizado na avaliação diagnóstica, com o objetivo de verificar se as atividades da segunda etapa promoveram aprendizagem e para comparar e analisar as questões abertas, após o fechamento de todas as atividades.

Em relação a avaliação formativa, essa aconteceu ao longo do desenvolvimento do trabalho tendo a frequência dos estudantes nos estudos, nas pesquisas e nos seminários, bem como a participação dos mesmos na elaboração de perguntas, nas respostas e nos comentários nas atividades de socialização e as resoluções de cálculos propostos, foram critérios de avaliação.

\section{Resultados e Discussão}

A segunda aplicação do questionário demonstrou que os estudantes adquiriram conhecimentos que os ajudarão no dia a dia com relação as medidas agrárias utilizadas no campo, pois as respostas foram bem diferentes daquelas do diagnóstico onde a maioria respondeu que ajudava apenas na prática de plantio e colheita, sendo observada nas respostas no pós-teste, que os mesmos já contribuíam com os cálculos matemáticos nas atividades do campo. Observou-se, ainda, a contribuição das atividades no que se refere a utilização da matemática no cotidiano, pois as respostas encontradas na avaliação diagnóstica foram que os estudantes não viam esta importância, tendo em vista que não sabiam como aplicar os cálculos de área aprendidos na escola aliados aos usados no campo, sendo observado na avaliação somativa, onde os educandos justificaram que era muito importante aprender matemática aliado as práticas do campo.

O resultado foi obtido, porque as atividades dos encontros, principalmente os de cálculos e prática no campo fizeram com que os estudantes pudessem aplicar o que aprendem na escola em seu cotidiano, contribuindo de certa forma para 


\section{DIVERS@!}

valorização dos conhecimentos científicos e sua aplicabilidade no cotidiano, bem como dos conhecimentos do campo e a relação existente entre eles.

\section{Conclusão}

As atividades desenvolvidas atingiram seu objetivo no sentido de instrumentalizar os estudantes a partir de conteúdos escolares definidos nas DCE's e ao mesmo tempo, atendendo as necessidades práticas do dia a dia das atividades agrícolas, ou seja, cálculos de área convencional aliados aos cálculos não convencionais, que por sua vez, são utilizados no campo.

Os resultados indicam que permitir o diálogo entre o saber científico e o saber popular, contribui com a formação do estudante, conforme afirmou Sacristan (2000) ao dizer que o professor não decide sua ação no vazio, mas no contexto de uma realidade de trabalho, ou seja, de acordo com a necessidade de seus educandos, bem como, contribuíram para desmitificação da rotulação de "atraso" ao se referir aos sabres do campo, como bem demostrou Machado (2009).

Em geral, concluiu-se que as atividades responderam as questões motivadoras e atingiu o objetivo proposto, isto é: buscar novas metodologias para construção de um currículo para escola do campo nucleado e por isso, o conteúdo "Medidas Agrárias" foi incorporado ao
Plano anual de Trabalho Docente (PTD) dos professores de matemática do Ensino Médio do Colégio, onde a pesquisa foi desenvolvida.

Enfim, a busca por metodologias, que integram a realidade local com os conteúdos escolares, não se esgota com esse trabalho, porém, a metodologia descrita demonstrou que é possível construir um currículo permitindo o diálogo entre os saberes e ao mesmo tempo, criar condições de aprendizagem para os estudantes.

\section{Referências}

BAGLI, P. Rural e urbano: harmonia e conflito na cadência da contradição. In: SPOSITO, M. E. B. \& WHITACKER, A. M. (Orgs). Cidade e campo: relações e contradições entre urbano e rural. São Paulo: Expressão Popular, 2006.

BRASIL. Senado Federal. Lei de Diretrizes e Bases da Educação Nacional: nº 9394/96. Brasília : 1996.

DUPAS, G. Economia global e exclusão social: pobreza, emprego, estado e o futuro do capitalismo. São Paulo, $2^{\mathrm{a}}$ ed. Editora Paz e Terra. 1999. 241p.

FERNANDES, B. M. Os campos da pesquisa em Educação do Campo: espaço e território como categorias essenciais. In: MOLINA, M. C. (Org.) Educação do Campo e Pesquisa: questões para reflexão. Brasília: Ministério de Desenvolvimento Agrário, 2006. pp. 27-39

HAMMEL, Ana Cristina; SILVA, Nilton José Costa; ANDRETTA, Ritamar. Escola em Movimento. A conquista dos Assentamentos. Colégio Estadual Iraci 


\section{DIVERS@!}

Salete Stronzak. Ed. Progressiva Ltda. Rio Bonito do Iguaçú. Pr. 2007.

http://www.mst.org.br/,http://pt.wikipedia.org/wiki/ Movimento_dos_Trabalhadores_Rurais_Sem_Ter ra. Consultado em abril de 2013.

http:/www.brasilescola.com/sociologia/mst.htm . consultado em abril de 2013.

MACHADO, I. F. A organização do trabalho pedagógico em uma escola do MST e a perspectiva da formação omnilateral. 2003. Tese (Doutorado) Faculdade de Educação, Universidade Estadual de Campinas, Campinas, SP.

SACRISTAN, Gimeno. O Currículo, uma reflexão sobre a prática. Porto Alegre: Editora Artmed, 2000. 